\title{
Empirical Research on Urbanization of Henan Province on the Increase in Farmers' Income
}

\author{
Zhang Tingting ${ }^{1, a, *}$, Wang Xue ${ }^{2, b}$ \\ ${ }^{1}$ Department of Economic Management, Anyang Institute of Technology, Anyang, China \\ ${ }^{2}$ Finance Office, Anyang Institute of Technology, Anyang, China \\ a896556051@qq.com, b309053913@qq.com
}

Keywords: Henan Province, Urbanization, Farmers' Income, VAR models

\begin{abstract}
In this paper, an empirical research on the relationship between urbanization of Henan Province and income of farmers is conducted by introducing VAR model and applying the data of urbanization and farmers' income in Henan province from 1978 to 2014. The results show that the higher the urbanization level, the greater the farmers' income, quantitatively, 1 percent increase in urbanization rate can lead to 2.87 percent increase in rural per capita net income. Therefore, Henan should follow the path to urbanization and continue to improve the urbanization level, perfect social security system and land management system, strive to develop tertiary industry and agriculture with distinctive features, and increase farmers' income through urbanization.
\end{abstract}

\section{Introduction}

The issue of "agriculture, rural areas and farmers" is a major social and economic issue during the transition period of China. The report of the 19th National Congress of the Communist Party of China clearly stated that the issue of agriculture and rural peasants is a fundamental issue concerning the national economy and the people's livelihood. We must always solve the problem of "agriculture, rural areas and farmers" as a party work. The most important thing. The core of the "three rural" problem is the peasants, and the key to the peasant problem is the increase in peasants' income. Therefore, promoting farmers' continuous income increase is a major task facing the new stage of China's economic development.

Henan Province is not only a large agricultural province, but also a large population province. The proportion of rural population is large. Among the population of 107.22 million in the province, the rural population accounts for 53.15\%, and more than $50 \%$ of the GDP depends on agriculture and related industries. With the rapid development of the economy, the per capita net income of farmers in Henan Province has also increased year by year. From 4,454 yuan in 2008, it has increased year by year. At the same time, from 2008 to 2018, the urbanization rate of Henan Province increased by 15.7 percentage points, an average annual increase of nearly 1.5 percentage points. By the end of 2018, the urbanization rate of permanent residents in the province had reached $51.7 \%$. This paper will establish an VAR model and use the two evaluation indicators of urbanization and peasant income to empirically study the relationship between urbanization and peasant income in Henan Province.

\section{Indicator selection and data source}

Based on the previous studies, this paper selects the data of Henan Province from 1978 to 2017, through cointegration test, Granger causality test and constructing VAR dynamic model to empirically analyze the relationship between urbanization and farmers' income in Henan Province. The urbanization rate of urbanization, that is, the proportion of urban population and total population in Henan Province, is quantified by the letter X, and the income of farmers is expressed by the per capita net income of farmers in Henan Province. In order to avoid the possible heterosce dasticity, the data is processed by natural logarithm. The processed data are recorded as LNX and 
LNY respectively. The following analysis uses the processed variables. This paper uses Eviews8.0 to model data processing. The selected data is mainly from the Henan Statistical Yearbook.

\section{The results of empirical analysis}

\subsection{Stationarity test}

Since the variables selected in this paper are all time series, we need to test the stability of the above variables before the analysis. The ADF unit root method is used to test, which lays the foundation for the following cointegration test.

From the ADF unit root test results, the ADF value of rural per capita net income is -2.660715 , which is greater than -3.540328 . Therefore, we should accept the null hypothesis that the unit root is present, indicating that the rural per capita net income is a non-stationary sequence, and the second-order difference is The sequence whose ADF value is less than 0.05 , we should reject the null hypothesis that the sequence after the difference is stationary. In the same way, we know that the urbanization rate is also a sequence after the second-order difference.

\subsection{Cointegration test}

Through the stationarity test, we know that the urbanization rate and the income of rural residents are the same order single sequence, so the cointegration test can be further carried out. The specific results are as follows.

Table1. Cointegration test

\begin{tabular}{lllll}
\hline \hline $\begin{array}{l}\text { Hypothesized } \\
\text { No. of CE(s) }\end{array}$ & Eigenvalue & $\begin{array}{l}\text { Max-Eigen } \\
\text { Statistic }\end{array}$ & $\begin{array}{l}0.05 \\
\text { Critical Value }\end{array}$ & Prob. $^{* *}$ \\
\hline \hline None * & 0.284286 & 12.04109 & 11.22480 & 0.0359 \\
At most $1{ }^{*}$ & 0.134329 & 5.193005 & 4.129906 & 0.0269 \\
\hline \hline
\end{tabular}

According to the Johansen cointegration test, the P-value of the null hypothesis that there is no cointegration relationship is 0.0070 , which is less than the standard value at the significance level of 0.05 . Therefore, we should reject the null hypothesis that there is no cointegration between the urbanization rate and the income of rural residents. The relationship, that is, the stable equilibrium relationship between the urbanization development of Henan Province and the growth of farmers' income, and the co-integration equation can be obtained as follows.

Table2. Cointegration equation

\begin{tabular}{ll}
\hline \hline Normalized cointegrating coefficients (standard error in parentheses) \\
LNY & LNX \\
1.000000 & -2.868627 \\
& $(0.22234)$ \\
\hline
\end{tabular}

From the cointegration equation, we know that in the long run, the relationship between farmers' income growth and urbanization development in Henan Province shows a change in the same direction. Specifically, for every one percentage point increase in the level of urbanization in Henan Province, the effect on farmers' income is 2.87 . \%. It shows that the development of urbanization in Henan Province is conducive to the improvement of farmers' income. Therefore, our province should strengthen urbanization reform and promote the further improvement of farmers' income.

\subsection{Construction of VAR model}

In the following, the dynamic relationship between urbanization development and peasant income growth in Henan Province is further studied by constructing VAR model. Based on this, impulse response function analysis and variance decomposition analysis are carried out. The optimal lag of the model is needed before the above analysis. The order is determined. This paper uses the majority principle to determine. From the majority principle, the optimal lag order of the VAR 
model is 2, so we construct the VAR (2) model. At the same time, we also need to test the stability of the model. The unit root method is used for the test. The results are as follows:

Inverse Roots of AR Characteristic Polynomial

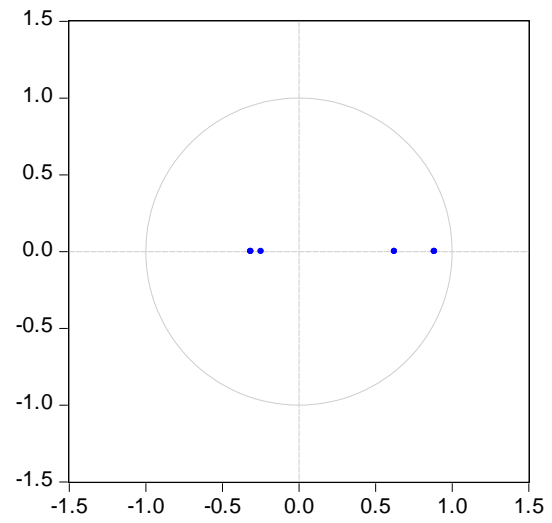

Figure 1. Construction of VAR model

All points fall within the unit circle, so we believe that the VAR model is stable and can perform impulse response function analysis and variance decomposition analysis.

\subsection{Analysis of impulse response function}

The analysis of impulse response function is to study how the impact of one unit on a variable will affect other variables. The analysis of variance decomposition is how much the impact of the impact on the other variables. The specific results are as follows.

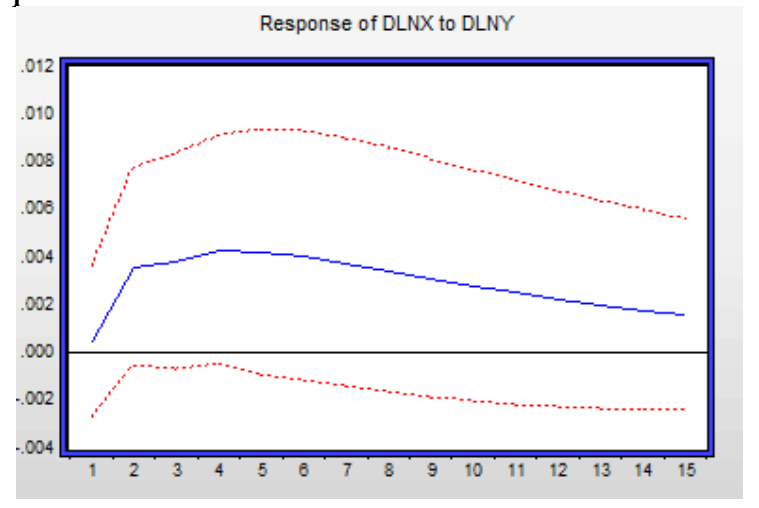

Figure 2. Impulse response function

From the analysis of the impulse response function of urbanization of Henan Province to the income of farmers, it can be seen that in the first phase of the positive impact of urbanization, the income of farmers is fluctuating, and this fluctuation reaches positive in the fourth period. The largest, followed by the trend of decreasing volatility, and finally showed a stable trend, the eighth period began to converge. In the long run, the development of urbanization in Henan Province has a positive effect on the income growth of farmers, consistent with the results of the cointegration equation.

\section{Conclusions and countermeasures}

Based on the above empirical analysis results, it can be concluded that there is a significant long-term equilibrium relationship between urbanization and peasant income in Henan Province. Specifically, the urbanization rate changes with the per capita net income of farmers, and the urbanization rate increases by 1 percentage point. The per capita net income of farmers increased by 2.87 percentage points. This shows that the urbanization of Henan Province has a significant effect on the growth of farmers' income. The higher the urbanization rate, the higher the income level of farmers, but this effect is one-way. Therefore, we must combine the actual situation of our province, 
adapt to local conditions, and gradually increase the level of urbanization, which in turn will drive the growth of farmers' income.

First, accelerate urbanization. Although some achievements have been made in the development of urbanization in Henan Province, the urbanization rate is still lower than the national average. In the middle six provinces, the income of farmers in Henan Province should be stable and rapid, and urbanization must be further accelerated. The development of development has realized the transfer of rural surplus labor, so that more farmers settle down in urban areas and continuously increase the wage income of farmers. Henan Province should according to the function and location of each city, rational division of labor, complement each other's advantages, optimize the spatial function layout, promote the development of industrial clusters, and improve infrastructure construction. The core of the city center drives the development of surrounding towns.

Second, there are many problems in housing, children's schooling, medical care, etc., while the rural areas become "hollow villages" and there are left-behind women. Children's problems. Therefore, it is necessary to continuously improve the quality of urbanization by reforming the household registration system and improving the social security system, so as to encourage more farmers to truly transform into urban populations, so that farmers who enter the city can enjoy the same social security, social welfare and medical security as the citizens. Obtain the same labor rights protection and compensation for work-related injuries, obtain the same housing subsidies and affordable housing, so that the children of migrant workers have the same educational opportunities. In addition, it is necessary to strengthen the vocational training of farmers so that farmers can acquire the ability to engage in other occupations in addition to agricultural production, thereby improving the professional competitiveness of farmers in urban areas and increasing the wage income of farmers.

Third, transform the industrial structure. Among the three major industries, the tertiary industry has the strongest absorption capacity for surplus labor. In 2018, the contribution rate of the tertiary industry in Henan Province is 50\%. The tertiary industry has become the first driving force for economic growth in Henan Province. Henan Province should seize the development opportunities of the national industrial restructuring and promote the integration and development of the first, second and third industries. The labor-intensive characteristics of the tertiary industry absorb more rural surplus labor, promote the transformation of industrial structure, encourage and support peasant employment or self-employment, broaden income-increasing channels, and increase farmers' income.

Fourth, cultivate new farmers. The report of the 19th National Congress pointed out that it is necessary to implement the strategy of rural revitalization, so that agriculture can become an industry with a head-on, let the peasants become attractive occupations, and turn the countryside into a beautiful home for living and working. Farmers have the desire to actively learn agricultural science and technology and advanced agricultural knowledge. The government must satisfy these wishes and organize practical training so that more farmers can receive vocational and technical education and cultivate new farmers. In addition, popularizing rural high school education will enable more peasant children to enter higher education institutions and lay a good foundation for cultivating new farmers.

\section{References}

[1] Ye Yumin. The Road to Urbanization in China - Economic Support and Institutional Innovation [M]. Beijing: The Commercial Press, 2002.

[2] Li Yining. A new way to increase farmers' income [J]. Rural Work Communication, 2012 (3).

[3] Wu Xuxiao. The evolution trend and policy analysis of urbanization level in Henan [J]. Regional Economic Review, 2013 (2).

[4] Yu Kaizhi, Huang Chuyu, Yu Jiyin. Analysis of the effect of urbanization on China's economic growth [J]. Finance and Economics, 2014 (7). 
[5] Cao Zhiqiang, Yuan Guizhen. Analysis of the Influence of Urbanization Process on Farmers' Income[J]. Economic Research Guide, 2014(17).

[6] Zhang Jinhua. Research on the relationship between urbanization, agricultural product circulation efficiency and farmers' income growth [J]. Business Economics Research, 2015 (33). 